\title{
Content of multimedia orientations of students: risks and ways of their pedagogical overcoming in the framework of social partnership
}

\author{
Tatiana Vlasova, Valentina Abraukhova*, Natalia Mamchits and Elena Egorova
}

Don State Technical University, 344000 Rostov-on-Don, Russia

\begin{abstract}
The purpose of the study is to analyze the content of multimedia orientations of students who are real users of virtual space of the university. In the article next problems are exposed:1)new concept is "content of multimedia orientations of students";2)multimedia risks of stude nts;3)the methods of overcoming of multimedia rrisks; 4) the model of social and pedagogical partnership; 5)the degree of multimedia orientations of students; 6) comparison of the obtained results with the research data related to the determination of students' religious negativity, the phenomenon of which was reflected in their preferences in the selection of virtual information. The article discusses the relationship of the fourth industrial revolution and the digital economy; virtualistics and information and communication technologies; e-education and distance learning in the context of foreign and domestic scientific discourse, which allowed the introduction of new concepts in the field of professional pedagogy. Particular attention is paid to the methodological justification of cooperation between the aggregate subjects: students and teachers in the process of overcoming multimedia risks on the basis of the developed innovative model of social and pedagogical partnership in the system of higher professional education.
\end{abstract}

\section{Introduction}

In a rapidly developing society of information and communication culture and the digital economy, the question of the risks posed in the phenomenology of the multimedia space, which is currently one of the central elements in all spheres of human life, from socioeconomic to personally intimate, is an acute question. "The principles of Art Nouveau in a risk society are suing industrial and social development," said W. Beck, which should be taken into account when organizing training. At the same time, "microelectronics allows reconnecting enterprises, branches and consumers into a single network over the

*Corresponding author: childrenpalace@mail.ru 
manufacturing sectors," which filled the reform of the foreign higher education system with information and communication technologies [1].Considering employers' demands for a high level of technological competencies among graduates, new standards and rules for social partnership in this direction were developed (P. Lempinen, 2013; Y. Wu, 2017) [2, 3]. Similar processes were discovered by us in the domestic education system, in particular, when studying the dynamics of employers' perceptions of the quality of competencies of graduates in the secondary vocational education system (T. Vlasova, V. Abraukhova, 2018) [4].Further reform of vocational education should take into account the general laws of development of the digital economy, information and communication culture, since employers, as social partners, in organizing and higher professional education insist on increasing the share of the information and communication component of the educational process. These facts confirm the relevance of the problem of this study: identifying the risks associated with the maximum immersion of modern youth in a virtual environment, which really hinders getting a quality education, and, in turn, requires the justification of pedagogical ways to overcome these risks, which cannot be done without analyzing the content of students' multimedia orientations.

\section{Review of scientific sources}

Foreign scientific discourse raises questions of the limited competencies acquired by university graduates (K. Hughes, 2007; R. Carlson, 2017) [5, 6], which is associated with the following factors: aging teaching staff who do not have time to master new scientific data, the inability of university science to fully respond to the request of the information era. In the Russian Federation, starting from the 90s of the XX century, these rather heatedly discussed issues related to the development of competencies, qualification frameworks, professional standards and other elements of professional education were resolved theoretically (I. Ivanenko, 2013; E. Rudneva , 2015) [7, 8], and at the legislative level (new generations of GEFs are approved).On the other hand, in the beginning of the 21 st century, the appeal to improve the quality of higher professional education was again especially acute in foreign countries in the situation of the so-called "fourth industrial revolution" (K. Schwab, 2011). The indicated problem is global and today remains unresolved. In this direction, we were not able to find holistic concepts in foreign and domestic sources, which set us an innovative goal related to an interdisciplinary approach to describe the interaction of the digital economy and the phenomenon of virtual education.

Let us formulate the position of scientists from various fields of scientific knowledge on general concepts. In the framework of the concept of the digital economy, which is the result of the "fourth industrial revolution" (4IR), it becomes attractive in terms of large-scale transformations in all spheres of life and, supposedly, in terms of its economic advantages. However, there are social challenges that, as a rule, are not advertised. In this regard, we will present an alternative point of view of D. Evstafiev on 4IR. For a "revolution", a "base" is needed, which, according to the author, does not exist, because its positive positioning, like the massive introduction of robotics and digital control technologies, reduces industry dependence on labor costs, gives an additional impetus to localize the real sector, and that is all. In fact, 4IR is “... globalization and universalization of the principles of" distributed "production and access to finance, since there is nothing fundamentally new in this approach: its key elements were tested back in the 1980s both at the production and management levels. $<\ldots>$ There are only prerequisites for the restructuring of some, but not all aspects in the functioning of the real sector of the world economy. Which will inevitably have serious social consequences. $<$... $>$ In fact, there is no real technological - and economic - basis for 4IR just as for the "revolution in industry" "(D. Evstafiev, 2017) [9]. For our study, these findings become the basis for studying the impact of the digital economy on vocational training in higher education.

Since it is necessary to "digitize" education in a modern transforming society, problems arise not so much of a practical as of a theoretical and methodological nature. In our opinion, 
the answers to these challenges also lie in the plane of partnership, which, according to J. Jefferson, brings the results of education closer to the world of work. At the same time, a new virtual apprenticeship, created jointly by universities and business, should be the answer to this problem based on the digital industry. Digital is no longer the future - it is the present. So, why, during such prosperity and growth, only less than $10 \%$ of graduates can find work in their chosen field? (J. Jafferson, (2013) [10]. Thus, an analysis of the sources shows that the relationship of employers with higher educational organizations should be built on the basis of a spiritual ontological model of social partnership (T.I. Vlasova, 2011, 2016, 2018) $[11,12,13]$ in the horizon of introducing innovative teaching tools, these tools should be based on the indicated trends of virtualistics, which will allow graduates to apply information and communication competencies not only in real business, production, but also in perspective their prospects. First of all, the solution to the problem lies in the plane of partnership between the main subjects: students and teachers, it is the latter that the content aspects of both individual and general multimedia orientations of students depend on.

\section{Methods of research}

We used the next methods of research : analysis of scientific sources and synthesis of scient ific ideas for the ground of content of multimedia orientations of students; description of co nception of virtual education and determination of multimedia risks of students; questionnai re of students for the purpose their multimedia orientations; comparing of the got results to data of the research, related to determination of religious negativism of students, the pheno menon of that affected their preferences at the selection of virtual information; ground and development of model of overcoming of multimedia risks on the basis of sociallypedagogical partnership (students + teachers). Respondents are students of a technical university (DSTU, Rostov-on-Don, 2018). A total number is 212 people, 127 of whom receive education in technical specialties (without specifying a profile) and 85 people in humanitarian specialities. According to anonymous questionnaires, respondents were divided as follows: men - 96 people, women - 116. Religious affiliation: out of the total: believers - 116 people, 9 of them chose the position "Islam," the remaining 107 people chose "Orthodoxy". Unbelievers - 96 people. In this case, we see a fairly close coincidence in gender, in the technical orientation of the future profession and in the students' affiliation with the faith. This conclusion will be further confirmed by other parameters for multimedia orientations and described in the next section of this article. The logic of further research required a comparison of respondents according to the parameter of religion, which was carried out by the authors of the article in 2017 (T.I. Vlasova, B.Ch. Meskhi, S.V. Smirnov) [14], since in the indicated year there were less unbelieving students. In this study, only firstyear students and exclusively psychological and pedagogical orientation of the future profession took part. In 2018, the number of non-believing students was $15.2 \%$ more, which was further taken into account when revealing the connection between this indicator and the orientation of the profession, since students with a technical orientation identified themselves as "unbelievers".

\section{Results and discussion}

The discussion in foreign and Russian science is conducted around the substantiation of the essence of virtual reality, e-education, multimedia learning. The difficulty of substantiating of pedagogical concepts is connected with the fact that in most cases the development of methods is based on cybernetics approaches, first of all. We need to use an integrative approach. So in philosophy, a separate line of research was formulated, and it was called 
"virtualistics" [15], and in psychology, cognitive psychologists [16] initially dealt with these problems.The ontological aspect of e-learning is associated with the "situational phenomenology of virtual objects" (V.L. Vasyukov, 2004) [15, p. 44]. First of all, a feature of these objects is that they depend on real objects, at least. The internal logic of their ontology is the following process: from potentiality through energy to their virtual entelechy, that is, completeness in its implementation. It is a form of virtual reality and a virtual mode of action. Therefore, in the case when the student is included in these forms and methods, imagining their real analogues, any process can be improved. In our case, we are talking about vocational training. On the other hand, one should avoid a formally schematic or exclusively object approach to explain the emergence of the virtual world, the so-called "technogenic artifact" (M. M. Kuznetsov, 2004) [15, p. 62-90], since, being a network phenomenon, virtualization of reality can either occur or not. In this case, it makes sense to study it as a dynamic process that is not always completed in the form of a virtual world. In this regard, the logic of the study involves its analysis from the point of view of psychological mechanisms, or, for example, from the point of view of the theory of autopoiesis (U. Maturano, F. Varelo, 70th of the XX century) as a self-reproducing intrapersonal system of network communication. Since there is a constant cognitive self-presentation of virtuality, its perception arises as a coherent (interdependent) process, where the boundaries between reality and virtuality of events, feelings and actions are erased.Under conditions of total cyber digitalization (R. Mayer, 2001) [16], there is a risk associated with the consolidation in a person of sensations of pleasure from illusory pseudo emotions that arise under the influence of modern teletechnologies and various kinds of simulacra. Once in the real world, faced with a real danger, such a "simplified professionalism" can lead to in effective actions. In the context of total electronic education, there is a risk associated with increased students' uncritical thinking in relation to false facts, to distorted information, which reflects the hidden virtualization of the picture of the world, the spread of pseudo-scientific pictures of the world, and the consolidation of mythological images. This together leads to unprofessionalism, and even, in extreme form, to a negative attitude towards life (suicide is inevitable due to the cognitive paradox).

So, multimedia risks: the lowered responsibility of personality; virtual convertibility of $r$ eality; unformed of transcendentness for students. From the point of view of the need to overcome these risks, it is advisable to organize multimedia training for students on the basis of cooperation between the main subjects of this process: the partnership of students and teachers, which is presented by us in the form of a model (Fig. 1).

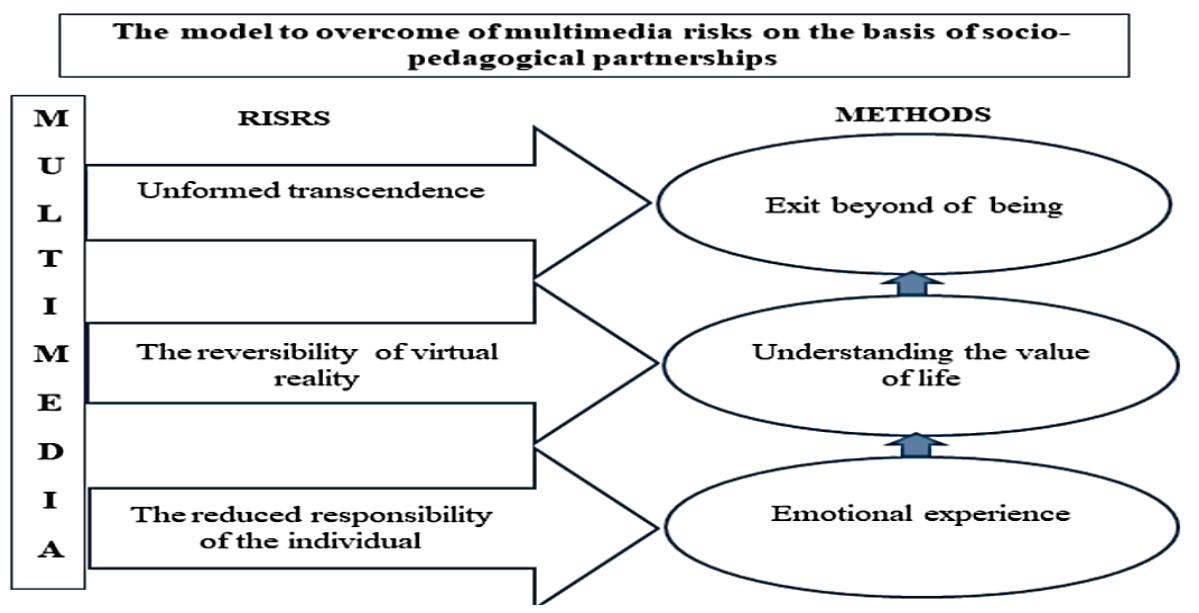

Fig. 1. Spiritual ontological cooperation of students and teachers in the process of e-education 
In the real study, we conducted the questionnaire of students and defined the degree of their virtual submerged on three blocks of vital functions: virtual communication, leisure/is rest and risk of practice. Such a theoretical reconstruction of the coherence of the cyber digitalization of education and the human inner world allowed us to use the indicator of religious negativity - "security / insecurity" (T.I. Vlasova, 2018) [14] as a methodological toolkit. In this study, we analyzed answers for only three blocks with the following options: Yes, Partially, and No. The mutual transition from the transcendence of an event through its potentiation to its radical transformation is a dynamic characteristic of students' multimedia intentions. In due time N.A. Nosov, as a methodological pair, substantiated two levels of reality: "one constant and one virtual" [17] (table 1).

Table 1. Analytical matrix of dynamic characteristics of multimedia orientations of students

\begin{tabular}{|l|c|c|}
\hline Block 1 - Media Communication & constant & virtual \\
\hline I like to chat with friends through social networks. & & + \\
\hline I like to receive information from the Internet. & + & + \\
\hline In my free time I like to hang out on the Internet. & & + \\
\hline I like to play media games & + & virtual \\
\hline I like to watch movies only on the Internet & constant & + \\
\hline Block 2 - leisure / relaxation & + & + \\
\hline I prefer to read books on the Internet & & + \\
\hline I love to play computer games & + & + \\
\hline I love to surf the internet virtually & + & + \\
\hline I like to take a selfie (my own photo) in any situation & + & + \\
\hline I prefer to play dangerous quests (story games) & + & + \\
\hline Block 3 - riskogenic practices & + & + \\
\hline I can organize an extreme trip & + & + \\
\hline I prefer to shop online & + & + \\
\hline I trust other people's media information & & + \\
\hline I trustreligiousmedia & & + \\
\hline $\begin{array}{l}\text { I trust the media information of the regional } \\
\text { geographical content }\end{array}$ & & + \\
\hline
\end{tabular}

\section{Conclusion}

Thus, undertaken a study allowed to the authors of the article:

1. To enter in the theory of education a new concept is "content of multimedia orienta tions of students as

dynamics process of transition from transcendence event by means of his potentialities to his radical transformation" on the basis of integrative approach

2. To define multimedia risks of students : at the emotional-sensual level - in reduced responsibility due to the scarcity of real experiences; at a cognitive level - the inability of 
consciousness to distinguish between reality and its virtual reversibility due to the total cyber usurpation of professions and life, including intimate aspects; at a spiritual level - in the absence of students' spiritual skills to go beyond their own limits of life due to the dominance of facilitated communication through multimedia.

3. To set forth the methods of overcoming of multimedia risks on the basis of cooper ation of teachers and students in the process of education: emotional experiencing, compreh ension of value of life, exit outside of life.

4. To determine the model of social and pedagogical partnership, which can be implemented in the electronic education system at a technical university, which will expand the external and internal horizons of self-development of the aggregate subjects.

5. To define the degree of virtual orientation of students on three blocks: virtual com munication, leisure/rest and risk of practice, that it must be used as a rich in content compo nent of trade education.

6. To educe the feature of perception of multimedia information believing and infidel students on the basis of index is "security / insecurity" in the world, that it can be used as a dialogue between them by teachers within the framework of sociallypedagogical partnership.

\section{References}

1. U. Beck, Risikogesellschaft (Frankfurt am Main, Suhrkamp,1986)

2. P. Lempinen, Social partnership in vocational education and training (ETF, 2013)

3. Y. Wu, HED, 1 (01), 22-32 (2017)

4. T. Vlasova, E. Krasnova, V. Abraukhova, N. Safontseva, JofSStER, 9 (1), 76-88 (2018)

5. K.P. Hughes, Remarks at the Business Partnerships in Higher Education Luncheon Hosted by the Indo-American Chamber of Commerce (2007)

6. R. Carlson, College-Business Partnerships Can Solve The Higher Education Affordability Crisis (2017)

7. I.A. Ivanenko, Vestnik YGU, 4, 46-50 (2013)

8. E.L. Rudneva, V.A. Ovchinnikov, NOMiRT, 133-150 (2015)

9. D. Yevstaf'yev, The Fourth Industrial Revolution: a propaganda myth or "sign of trouble"? (2017)

10. J. Jafferson, Could social media bridge the divide between business and education? (2013)

11. T.I. Vlasova, MS. 4 (4), 8 (2016)

12. T.I. Vlasova, IVSPU, $\mathbf{1} / \mathbf{1 0 5}, 24-30$ (2016)

13. T.I. Vlasova, V.V. Abraukhova, NESR:NMiT, 17-21 (2018)

14. T.I. Vlasova, B.C. Meskhi, S.V. Smirnov, BPiKAinSM, 59-85 (2018)

15. Virtualistics: existential and epistemological aspects (Moscow, 2004)

16. R.E. Mayer, Multimedia learning (Cambridge University Press, New York, 2001)

17. N.A. Nosov, PrLV, 12 (2001) 